- $20 \%$ of parents/carers said staff were not good at working together or with others e.g. GP, school/nursery

- $37 \%$ said the information they were given was hard to understand

The team reflected on the Round 2 PREM and worked with the RCPCH Children and Young People's Engagement Team on an Engagement Plan for round 3.

Between April and June 2018, 130 children and family members took part in 'clinic chats' and gave their views on 'service contactability' and family mental health. 10 hospitals were visited and two family days held. Children as young as 3 contributed. Reports from clinic chats were reviewed by Epilepsy12 youth advocates who identified top priorities via thematic analysis as follows:

- Schools (support, good care plans, awareness, training, visits from nurses)

- Support for worries and anxieties (Why me? transition, mental health, messages of hope and coping strategies)

- Face to face support (value of group work/support groups, engagement sessions, parent/carer groups, young people groups, more time with health workers)

- Positive adult relationships (school, clinicians, specialist nurses, family, support workers)

- More services (mental health and wellbeing, weekends/ evening non-emergency support, home visits, support groups)

- Practical help (lifestyle tips, family-based training, coping mechanisms, products to explain epilepsy to children)

- Emerging topics (employment, independence)

Sibling carers aged 3-11 also contributed views and created Epilepsy Superheroes who could be on hand with super powers if someone had a seizure.

Two of the youth advocates delivered a 75 -minute session on the clinic chat themes at the Epilepsy12 National Conference in June 2018 to over 160 paediatric epilepsy specialists. This CYP-led session received overwhelmingly positive support from attendees.

Youth Advocates are now developing a quality improvement project relating to support for anxieties and worries and will report on it at the 2019 Epilepsy12 National Conference.

\section{GP297 EVALUATION OF AN EARLY BIOCHEMISTRY MARKER OF RENAL INJURY IN OBESE CHILDREN}

Olivera Jordanova*, Aspazija Sofijanova, Aleksandra Janchevska, Silvana Naunova, Danilo Nonkulovski. University Children Hospital, Skopje, Macedonia, the Former Yugoslav Republic of Macedonia

\subsection{6/archdischild-2019-epa.356}

Background The obesity is the most prevalent nutrition-related disorder in children and becomes a major health issue worldwide. An increased risk of renal injury in children has been associated with overweight and obesity.

Objective To investigate the renal tubular function and early kidney injury in obese pediatric patiens.

Methods The $57(\mathrm{M}: \mathrm{F}=32: 25)$ patients from University Children Hopital-Skopje have been investigated from December 2016 y till March 2019y. They have been diveded in 2 groups: a group of thirty seven obese (body mass index (BMI) $\mathrm{z}$-score $\geq 2$ ) patiens ( $\mathrm{M}: \mathrm{F}=20: 17)$, and the control group of twenty non-obese children $(\mathrm{M}: \mathrm{F}=12: 8)$ with BMI $z$-score $\leq 2$. The blood samples have been collected in the morning, after an overnight (at least $8 \mathrm{~h}$ ), for measurements of complete blood count and biochemical parameters, including serum concentrations of creatinine, fasting glucose and lipid profile. The spot urine samples have been collected to assess NGAL levels as renal injury marker, and have been performed by Chemiflex (Abbott Architect I 1000 sr).

Results The serum concentrations of all examined parameters have been increased in the obese group, while only the HDL cholesterol levels have been decreased, compared to those in non-obese controls. The levels of analysed urine NGAL concentrations have been elevated in the obese group of children.

Conclusions Herein, in our study, we present the increased concentrations of NGAL in urine in the obese children compared to non-obese group of patients. We may confirm that urinary NGAL is useful and an early reliable marker for detection of renal damage in the obese pediatric patiens.

\section{P1 AN ANALYSIS OF PAEDIATRIC BURN AND SCALD PRESENTATIONS, CLINICIAN DOCUMENTATION OF THE RELEVANT CRITERIA NEEDED TO CONSIDER NON- ACCIDENTAL INJURY AND SOCIAL WORK OUTCOMES IN A PAEDIATRIC ACCIDENT AND EMERGENCY DEPARTMENT}

${ }^{1}$ Karen Kelleher* , ${ }^{1}$ Pauline Deacy, ${ }^{2}$ Susan Swan, ${ }^{1}$ Turlough Bolger. 'Paediatric Accident and Emergency Department, Tallaght University Hospital, Dublin, Ireland; ${ }^{2}$ Paediatric Social Work Department, Tallaght University Hospital, Dublin, Ireland

\subsection{6/archdischild-2019-epa.357}

Aims Analysis of paediatric burns \& scald presentations and Social Work outcomes in a paediatric Accident and Emergency Department (A\&E) over the course of six months.

Methods An audit was completed over a six month period in partnership with the Social Work (SW) Department. This audit included a review of all presentations to the A\&E with a discharge diagnosis including a burn or scald by children aged under 16 years. The SW Department initially reviewed all referrals and identified 8 key criteria which should be considered during medical review of burn/scald presentations. The audit analyses the application by Medical Staff of these key criteria during burn/scald medical reviews. It also reviewed the frequency of accurate and comprehensive documentation of the same. Consideration of these 8 criteria is paramount when identifying child protection concerns associated with burn \& scald presentations.

Results 70 cases were identified during the audit period. $66 \%(n=46)$ of patients were under the age of 5 years old, with a mean age of 4.6 years overall. Audit results indicated that $0 \%$ of cases had clearly documented consideration of the 8 key areas during medical review. In the entire group, 93/560 (17\%) of these individual questions were clearly documented in the medical notes. In $354 / 560$ (63\%) of these individual questions, it could be inferred from the notes that the healthcare provider had considered this question.

During the time of the audit, it was departmental policy to routinely refer all children under the age of 5 years presenting with burns for social work review. There were 52 (74\%) social work referrals made. Of these, there were 7/ 